\title{
Tatsuya Kobayashi, Dade Lunsford (Eds), Progress in Neurosurgery Series-Vol. 23 Pineal Region Tumors, Diagnosis and Treatment Options
}

\author{
146 pp, 58 figures, Hardcover, ISBN: 978-3-8055-9077-8, Karger
}

\author{
Nicolas de Tribolet
}

Received: 22 October 2009 / Accepted: 28 October 2009 /Published online: 28 November 2009

(C) Springer-Verlag 2009

The introduction is a presentation of the statistical analysis of pineal tumors based on the data of the brain tumor registry of Japan. The frequency of pineal tumors in Japan is five times as high as in western countries.

The first section deals with Tumors of Pineal Cell Origin.

The first chapter deals with the pathology of pineal parenchymal tumors including immunohistology and electron microscopy. It ends with a brief account of genetic alterations. The second chapter of this section describes the occipital transtentorial approach and combined treatments of pineal parenchymal tumors. It also includes a brief description of histopathological findings. The third chapter addresses the role of streotactic radiosurgery in the management of pineal parenchymal tumors.

The second section deals with Tumors of Germ Cell Origin.

The first chapter of this section describes the pathology of these tumors including their histogenesis and classification as well as a brief account of genetic alterations; then, follows a chapter on the general management of these tumors and another one on the strategy of combined treatment of germ cell tumors with a classification according to prognosis. The next chapter is on radiation therapy and includes a review of prospective studies with chemotherapy and radiation, followed by a chapter on stereotactic radiosurgery for pineal and related tumors (germ cell as well as pineal parenchymal tumors). The next chapter is a proposal for a modern strategy with radiation and chemotherapy. The last chapter deals with the quality of life of extremely long-time germinoma survivors mainly treated with radiotherapy.

This book provides a good picture of the state of the art in the management of pineal tumors. From the purely technical neurosurgical point of view, I missed the description of the infratentorial supracerebellar approach. The volume has the drawback of a multi-author book with some repetitions from one chapter to another. It can be of interest for neurosurgeons, radiotherapists, and medical oncologists.

N. de Tribolet $(\square)$

Neurochirurgie, HUG,

1211 Geneva, Switzerland

e-mail: nicolas.detribolet@unige.ch

N. de Tribolet

University of Geneva,

Geneva, Switzerland 